\title{
PERANAN KEPERCAYAAN KEPADA PENJUAL DAN LABEL HALAL TERHADAP MINAT BELI DAGING HALAL
}

\author{
Sumadi \\ Email : sumadi@uii.ac.id \\ Program Studi Manajemen Fakultas Ekonomi \\ Universitas Islam Indonesia Yogyakarta
}

\begin{abstract}
This aimed of this study is to explain the empiricly of factors that influence the purchase intention of halal-meat by Moslem consumers. This research used Fishbein and Ajzen's Theory of Reasoned Action (TRA) as a model. There are four latent variables that being used to construct this model. Purchase intention of halal-meat was predicted to be influenced by attitude, salesperson trust and halal label. While the salesperson trust and halal label was the antecedent that influence the attitude of halal-meat. The method used halal-meat as the object, population that used are adult or married Moslem consumers in Indonesia with the sample is women buyer. Data collected used convenience approach. The sample was 300 respondents in Yogyakarta, Surabaya and Jakarta. Empirical data analyzed with Structural Equation Model (SEM) Amos. The research result explained that there is positive and significant influence between salesperson trust and label-halal toward attitude, and attitude is positive and significant influence purchase intention of halal-meat. While, the salesperson trust had significant negatively toward purchase intention of halal-meat. In other side halal-label is not significantly influence consumer's attitude toward halal-meat.
\end{abstract}

Keywords: Purchase Intention, Halal Meat, Salesperson Trust, Halal-Label, Theory of Reasoned Action

\begin{abstract}
Abstrak:
Penelitian ini bertujuan untuk menjelaskan secara empiris faktor-faktor yang mempunyai pengaruh terhadap minat beli daging halal bagi konsumen muslim. Penelitian menggunakan model Theory of Reasoned Action (TRA) dari Fishbein dan Azjen. Ada empat variabel latent yang digunakan untuk membangun model. Minat beli daging halal diprediksi dengan menggunakan sikap, kepercayaan terhadap penjual dan label halal. Sementara kepercayaan kepada penjual dan label halal sebagai anteseden yang mempengaruhi sikap pada daging halal. Metodologi penelitian menggunakan daging halal sebagai obyek penelitian, populasi adalah pembeli daging dengan jenis kelamin wanita, konsumen muslim di Indonesia, sudah dewasa atau menikah. Data dikumpulkan dengan menggunakan metode nonprobability sampling cara convenience. Jumlah sampel sebanyak 300 responden dari wilayah Yogyakarta, Surabaya dan Jakarta. Data empiris dinalisis dengan Structural Equation Model (SEM) Amos. Hasil penelitian menjelaskan bahwa ada pengaruh yang positip dan signifikan antara kepercayaan kepada penjual dan label halal terhadap sikapnya, dan sikapnya mempunyai pengaruh yang positip signifikan terhadap minat beli daging halal. Sementara, kepercayaan kepada penjual mempunyai pengaruh yang signifikan dan negatip terhadap minat daging halal. Disamping itu label halal tidak mempunyai pengaruh yang signifikan terhadap sikap pada daging halal.
\end{abstract}

Kata-kata kunci: Minat beli, Daging halal, Kepercayaan kepada penjual, Label Halal, Theory of Reasoned Action

\section{PENDAHULUAN}

Produk dengan jaminan halal merupakan persyaratan pertama untuk dapat diterima dengan baik oleh konsumen muslim (Riaz, 1994; Riaz dan Chaudry, 2004). Produk adalah segala sesuatu yang dapat ditawarkan kepada konsumen untuk memenuhi kebutuhan dan keinginan. ( Kotler dan Keller, 2012, Kotler dan Amstrong, 2016). Salah satu jenis produk yang ditawarkan kepada konsumen muslim adalah daging. Agama Islam, tidak melarang bagi penganutnya untuk makan daging, dengan syarat termasuk daging halal (Abdullah, 2013). Perintah untuk mengkonsumsi makanan halal, ada beberapa yang disebutkan dalam Al Qur'an, salah satunya tersebut dalam QS Al Baqoroh ayat 168 sebagai berikut: 


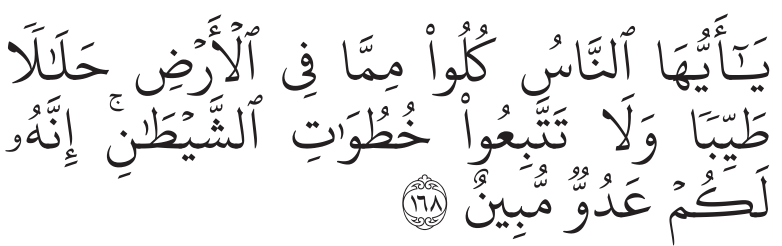

"Hai sekalian manusia, makanlah yang halal lagi baik dari apa yang terdapat di bumi, dan janganlah kamu mengikuti langkah-langkah syaitan; karena Sesungguhnya syaitan itu adalah musuh yang nyata bagimu."

Daging halal dikategorikan sebagai produk yang memiliki sifat khusus, artinya ada beberapa binatang yang dagingnya dilarang (haram) untuk dimakan bagi pemeluk agama Islam seperti babi dan binatang yang bertaring (Kaleli, 2010). Selain itu, ada juga daging yang berasal dari jenis binatang yang dagingnya halal menurut syariah Islam, tetapi status halal (lawful) dapat berubah menjadi haram ketika proses penyembelihan atau pengadaannya tidak sesuai dengan syariah Islam, yaitu ketika binatang tersebut telah mati terlebih dahulu sebelum disembelih sehingga berstatus sebagai bangkai, atau cara penyembelihannya tidak sesuai dengan ajaran agama Islam, yaitu ketika menyembelih binatang tersebut, orang yang melakukannya tidak mengatas namakan Allah SWT (Mukhtar and Butt, 2012)). Sifat halal daging adalah asli (original), artinya tidak boleh tercampur atau terkontaminasi dengan barang yang haram, baik karena alat yang digunakan maupun proses distribusinya (Bonne dan Verbeke, 2008).

Muslim adalah sebutan bagi orang yang memeluk agama Islam. Jumlah penduduk muslim di Indonesia adalah 207.176.162 orang atau $87,18 \%$ (BPS, 2014) dan merupakan porsi yang paling besar dibandingkan dengan pemeluk agama lain. Jumlah penduduk muslim yang relatif besar ini merupakan potensi pasar yang besar bagi produk-produk yang membutuhkan persyaratan halal menurut hukum Islam. Oleh sebab itu penciptaan dan penyediaan produk dengan kategori halal sudah seharusnya menjadi pertimbangan dan strategi bagi produsen atau pemasar yang sebagian besar konsumennya adalah muslim.

Penelitian tentang minat dan perilaku beli daging halal telah dilakukan oleh beberapa peneliti terdahulu (Bonne et al. ,2007; Bonne dan Verbeke, 2008: Ahmed, 2008). Namun penelitian yang mengangkat faktor latar belakang terhadap minat yang terdiri dari kesadaran individu, kepercayaan kepada penjual, label halal dan dilakukan di Indonesia adalah merupakan sesuatu yang baru pertama kali ini dilakukan.

Walaupun fakta menunjukkan bahwa sebagian besar penduduk dan penjual di Indonesia adalah muslim, hal ini bukan berarti untuk mendapatkan daging atau produk halal demikian terjamin. Banyak produk-produk makanan di Indonesia saat ini yang tidak terjamin benar-benar halal (Apriyantono, 2012 ). Dengan demikian seorang muslim di Indonesia perlu usaha (effort) yang sungguh-sungguh, cermat dan hati-hati untuk mendapatkan daging yang benar-benar halal sesuai dengan syariah Islam. Oleh sebab itu dianggap penting untuk melakukan penelitian yang berhubungan dengan bagaimanakah konsumen di Indonesia untuk menentukan menentukan keyakinan, sikap dan minatnya untuk membeli daging halal. Sehubungan dengan hal ini, maka penelitian ini bertujuan untuk mengetahui peranan kepercayaan kepada penjual dan label halal sebagai latar belakang dalam menjelaskan sikap dan minatnya.

\section{KAJIAN PUSTAKA DAN HIPOTESIS}

Dasar teoritis yang digunakan untuk model penelitian ini adalah Theory of Reasoned Action (TRA) dari Fishbein dan Azjen (1975). Theory of Reasoned Action (TRA) menyatakan bahwa minat individu untuk berperilaku dipengaruhi oleh sikapnya terhadap obyek atau perilaku tersebut dan norma subyektifnya. Namun dalam kajian ini peneliti hanya membatasi pada pengaruh sikap terhadap minat beli dengan menggunakan 2 antesedent, yaitu kepercayaan kepada penjual dan label halal. Theoritical framework penelitian ini adalah: 


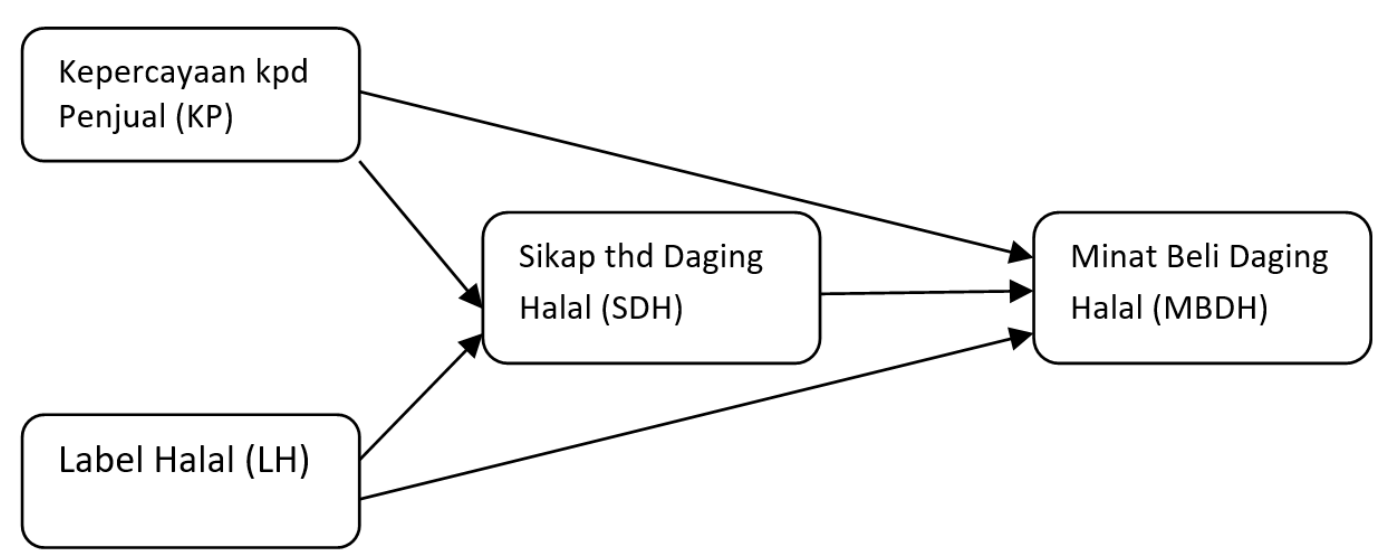

Gambar 1 Kerangka Teoritis

\section{Minat beli daging halal}

"We have defined intention as a person location on a subjective probability dimension involving a relation between himself and some action. Behavioral intention, therefore, refers to a person's subjective probability that he will perform some behavior" (Fishbein dan Ajzen, 1975). Minat sebagai disposisi tingkah laku, yang hingga terdapat waktu dan kesempatan yang tepat, akan diwujudkan dalam bentuk tindakan (Fishbein, 2005). Feldman (1995) menyatakan bahwa minat adalah rencana atau resolusi individu untuk melaksanakan tingkah laku sesuai dengan sikap mereka. minat merupakan suatu keadaan bagi individu untuk melakukan sesuatu perbuatan di masa depan (Berkowitz, 1972). Minat merupakan prediktor yang baik terhadap perilaku seseorang di masa yang akan datang (Fishbein, 2005).

\section{Sikap terhadap daging halal}

Sikap adalah disposisi untuk berespon secara favourable atau unfavorable terhadap benda, orang, institusi atau kejadian (Fishbein dan Ajzen, 1975). Sikap adalah suatu bentuk evaluasi atau reaksi perasaan, sikap seseorang terhadap obyek adalah perasaan mendukung atau memihak (favourable) atau perasaan tidak mendukung (unfavourable) obyek tersebut (Berkowitz, 1972). Sikap terbentuk karena adanya 3 komponen yaitu kognitif, afektif dan konatif (Fishbein dan Ajzen, 1975).

Komponen kognitif berhubungan dengan keyakinan (belief) seseorang mengenai obyek sikap, baik yang bersifat positif atau negatif (Fishbein dan Ajzen, 1975). Selanjutnya Ajzen (2005) menyatakan komponen afektif menyangkut masalah emosional dan menjelaskan evaluasi dan perasaan obyek sikap. Umumnya reaksi emosional yang merupakan komponen afektif ini banyak ditentukan oleh keyakinan atau apa yang diyakini benar atau salah atas suatu obyek. Komponen konatif adalah kecenderungan tingkah laku, intensi, komitmen dan tindakan yang berkaitan dengan obyek sikap. Sikap merupakan suatu disposisi individu untuk berperilaku yang dasarnya adalah belief dan evaluasi terhadap suatu obyek, orang, atau kejadian yang kemudian diekspresikan dalam bentuk kognitif, afektif dan konatif (Fishbein dan Ajzen, 1975).

Beberapa hasil penelitian dapat menjelaskan terdapat pengaruh positif dan signifikan antara sikap terhadap minat untuk membeli daging atau produk halal (Bonne et al., 2007; Lada et al., 2009; Syah dan Sayuti, 2011; Mukhtar dan Butt, 2012; Abdul, 2014). Sedangkan hasil penelitian Jusmaliani dan Nasution (2008) menemukan hasil tidak ada pengaruh antara sikap dengan minat beli untuk mengkonsumsi daging halal. Sehubungan dengan hal ini maka dikemukakan:

H1: Ada Pengaruh positip antara Sikap Terhadap Daging Halal kepada Minat belinya.

\section{Kepercayaan kepada Penjual}

Dalam konteks penelitian ini, kepercayaan kepada penjual didefinisikan sebagai suatu penilaian dan kesediaan untuk mengalihkan dan menerima resiko seseorang terhadap subyek penjual atau penyedia produk. Beberapa hasil penelitian menjelaskan bahwa ada pengaruh positip dan signifikan antara kepercayaan kepada penjual daging yang muslim dengan sikap dan minat membeli 
daging dan produk halal (Bonne dan Verbeke, 2008; Ahmed, 2008; Tieman et al., 2013; Tieman dan Ghazali, 2014; Ghazaly, 2013). Hipotesis ini:

H2: Kepercayaan kepada penjual berpengaruh positip kepada sikap terhadap daging halal

H3: Kepercayaan kepada penjual berpengaruh positip kepada minat beli daging halal

\section{Label Halal}

Label halal adalah keterangan yang berupa gambar, tulisan atau kombinasi keduanya yang memuat informasi tentang barang atau pelaku usaha telah memenuhi syarat di izinkan berdasarkan syariah Islam. Beberapa hasil penelitian telah menyatakan bahwa terdapat pengaruh yang positip dan signifikan antara label halal produk terhadap sikap dan minat belinya (Ireland dan Rajazabdeh 2011; Abdul dan Vui, 2012; Abdul, 2014). Penelitian ini mengajukan hipotesis,

H4: Label halal produk daging memiliki pengaruh kepada sikap terhadap daging halal.

H5: Label halal produk daging memiliki pengaruh kepada sikap terhadap daging halal.

\section{METODE PENELITIAN}

Penelitian diawali dengan exploration study yang berupa studi pustaka dan pengamatan konsumen. Setelah itu dilakukan Focus Group Discussion (FGD) dengan target populasi di daerah penelitian. Berdasarkan hasil FGD, diperoleh informasi bagaimana cara konsumen untuk memperoleh daging halal. Untuk mendapatkan daging halal mereka percaya kepada penjual melalui sinyal atau tanda-tanda, misalnya penjual yang beragama Islam, di kios atau tokonya dipasang label halal. Berdasarkan temuan ini, maka peneliti selanjutnya mengembangkan dalam sebuah model penelitian.

\section{Populasi dan Sampel}

Populasi penelitian adalah konsumen muslim di Indonesia yang membeli dan mengkonsumsi daging, sudah dewasa atau menikah, memiliki pengetahuan dan pemahaman persyaratan daging halal secara Syariah Islam. Populasi termasuk kategori unristricted.

Sampel penelitian adalah pembeli daging dengan jender wanita, dengan alasan kebiasaan yang melakukan belanja bahanbahan makanan, termasuk daging di Indonesia adalah wanita. Tiga kota dengan penduduk di atas 1 juta orang dipilih sebagai sampel, yaitu Yogyakarta, Surabaya dan Jakarta. Masingmasing kota diambil 100 respoden, sehingga jumlah sampel sebanyak 300 responden dengan purposive sample dan non probability sampling dengan pilihan convenience.

\section{Variabel Penelitian dan Pengukuran}

Analisis data menggunakan alat Structural Equation Modelling (SEM), oleh karena itu variabel penelitian dibedakan menjadi variabel eksogen (bebas) dan endogen (tergantung). Variabel Eksogen terdiri dari 2 variabel, yaitu Kepercayaan kepada Penjual (KAP) dan Label Halal atau Ekstrinsik Produk (EP). Sedangkan variabel endogen (tergantung), yaitu Sikap terhadap Daging Halal (SDH) dan Minat untuk Beli Daging Halal (MDH).

Pengujian kuesioner dilakukan dengan tryout menggunakan 30 responden. Berdasarkan hasil perhitungan koefisien Pearson Correlation semua indikator hasil angka sig. lebih kecil dari 0,05. Dengan demikian dinyatakan valid. Sedangkan angka koefisien Cronbach Alpha untuk semua variabel di atas 0,60 , dengan demikian dapat dinyatakan reliable (Malhotra, 1996).

\section{Rancangan Analisis}

Prosedur analisis data dimulai dengan pengujian terhadap kualitas data, pengujian konfirmatori variabel penelitian, uji model struktural dan analisis. Untuk menguji hipotesis adalah dengan memperhatikan hasil standardized coefficient path, critical ratio dan probability value. Untuk menghitung dan menganalisisnya peneliti menggunakan pendekatan alat analisis teknik Structural Equation Modelling (SEM) Amos. 


\section{HASIL PENELITIAN DAN PEMBAHASAN}

\section{Pengujian Kualitas Data}

Pengukuran kualitas data diuji dengan pendekatan normalitas data, outlier dan multicolinearity. Hasil pengujian normalitas data menunjukkan angka critical skweness antara - 0,077 sampai dengan -1,529. Angka yang di bawah batas nilai signifikansi $1 \%$ sebesar $\pm 2,58$, dapat dinyatakan normal (Ferdinand, 2006) . Dengan demikian berdasarkan angka yang diperoleh data memenuhi syarat normal. Hasil pengujian outlier menghasilkan angka mahalanobis distance (distance $\chi^{2}$ ) sebesar 14,622 sampai 28,177 . Nilai $\chi^{2}$ yang berada dibawah nilai kritis dinyatakan tidak bermasalah ( Ghozali, 2013). Angka tabel $\chi^{2}$ jumlah data, banyaknya indikator dan tingkat signifikansi pengujian untuk $\chi_{(14: 0,01)}^{2}=29,17$, sehingga tidak ada outlier pada data. Sedangkan untuk pengujian multicoliniearity, apabila angka hasil analisis determinan matrik kovarian sangat kecil atau sangat dekat dengan nol artinya tidak ada masalah (Ghozali, 2013). Hasil analisis dan perhitungan menunjukkan angka berkisar antara 0,397 sampai 0,891 sehingga tidak terjadi multicollinearity.

\section{Analisis Validitas dan Reliabilitas}

Pengujian yang dilakukan adalah uji validitas konvergen (convergent validity) dan reliabilitas konstruk (construct reliability). Pengujian validitas konvergen dilakukan dengan melihat hasil loading factor $\left(\lambda_{\mathrm{i}}\right)$, dan angka probability value nya. Bila angka probability value lebih kecil dari 0,05, maka indikator dinyatakan valid (Hair et al., 2006). Sedangkan untuk reliabilitas konstruk dihitung dengan indeks reliabilitas instrument yang digunakan (composite reliability), bila nilainya $\geq 0,70$ maka telah memenuhi persyaratan baik (Byrne, 2010). Hasil perhitungan dan analisis validitas dan reliabilitas dapat disimpulkan bahwa indikator - indikator dan kontruk latent yang dipergunakan untuk penelitian memenuhi kriteria valid dan reliabel.

\section{Analisis Measurement Model}

Measurement Model adalah model pengukuran untuk menguji kesesuaian atau mengkonfirmasi indikator-indikator atau manifest dari sebuah variabel latent terhadap dua atau lebih variabel penelitian (Hair, et al.,2006). Jumlah variabel latent penelitian ada 4 buah, dan masing-masing variabel latent memiliki beberapa indikator. Hasil pengujian kesesuaian (goodness of fit) measurement model variabel latent dengan melihat angka Chi-Square, probability, CMIN/DF, RMSEA, GFI, TLI dan CFI memenuhi persyaratan (cut off). Hal ini seperti yang disampaikan pada Tabel 1. Dengan demikian model memenuhi kriteria goodness-of-fit.

Tabel 1. Pengujian Goodness of Fit per Variabel

\begin{tabular}{|c|c|c|c|c|c|c|c|c|}
\hline Variabel & $\begin{array}{c}\chi^{2} \\
\text { sangat } \\
\text { kecil }\end{array}$ & $\begin{array}{c}P \\
(\geq 0,05)\end{array}$ & $\begin{array}{l}\text { CMIN/ } \\
\text { Df } \leq 2\end{array}$ & $\begin{array}{c}\text { RM } \\
\text { SEA } \\
\leq \mathbf{0 , 0 8}\end{array}$ & $\begin{array}{c}\text { GFI } \\
\geq 0,90\end{array}$ & $\begin{array}{c}\text { TLI } \\
\geq 0,95\end{array}$ & $\begin{array}{c}\text { CFI } \\
\geq 0,95\end{array}$ & Keterangan \\
\hline $\begin{array}{l}\text { Kepercayaan } \\
\text { pada Penjual }\end{array}$ & 0,260 & 0,063 & 0,018 & 0,076 & 0,968 & 0,902 & 0,945 & Baik \\
\hline Label Halal & 0,546 & 0,761 & 0,273 & 0,001 & 0,999 & 1,022 & 1,000 & Baik \\
\hline $\begin{array}{l}\text { Sikap } \\
\text { terhadap } \\
\text { daging halal }\end{array}$ & 0,890 & 0,110 & 0,056 & 0,043 & 0,982 & 0,976 & 0,988 & Baik \\
\hline Minat & 1,641 & 0,20 & 1,641 & 0,046 & 0,997 & 0,981 & 0,997 & Baik \\
\hline
\end{tabular}

Sumber: Analisis Data Primer

\section{Persepsi Responden terhadap Variabel Penelitian}

Ada 4 variabel yang diminta untuk dinilai oleh responden, jenis dan hasil skore rata- rata penilaian responden seperti pada Tabel 2 berikut ini.

Persepsi penilaian responden untuk kepercayaan kepada penjual termasuk kategori sedang, dengan skore 3,779. Label 
halal yang berupa sertifikat, tanda atau logo halal berdasarkan penilaian mereka termasuk kategori tinggi, dengan skore 4,343. Sikap terhadap daging halal dan minat beli daging halal dinilai tinggi, ini dapat dilihat dari skore penilaian mereka yaitu 4,358 dan 4,422 .

Tabel 2 Penillaian Variabel oleh Responden

\begin{tabular}{clc}
\hline No & \multicolumn{1}{c}{ Variabel } & Mean \\
\hline 1 & Kepercayaan kepada Penjual & 3,779 \\
2 & Label Halal & 4,343 \\
3 & Sikap terhadap daging halal & 4,358 \\
4 & Minat beli daging halal & 4,422 \\
\hline
\end{tabular}

Sumber: Analisis Data Primer

Hasil Analisis Model Persamaan Struktural dihitung dengan alat analisis SEM Amos. dan Uji Hipotesis

Gambar struktural secara diagramatis dan

Pengujian dimulai dengan menghubungkan antar variabel-variabel sesuai dengan model yang dibangun. Data penelitian selajutnya besaran angka angka koefisien regresi dan angka koefisien Goodness Of Fit (GOF) adalah sebagai berikut:

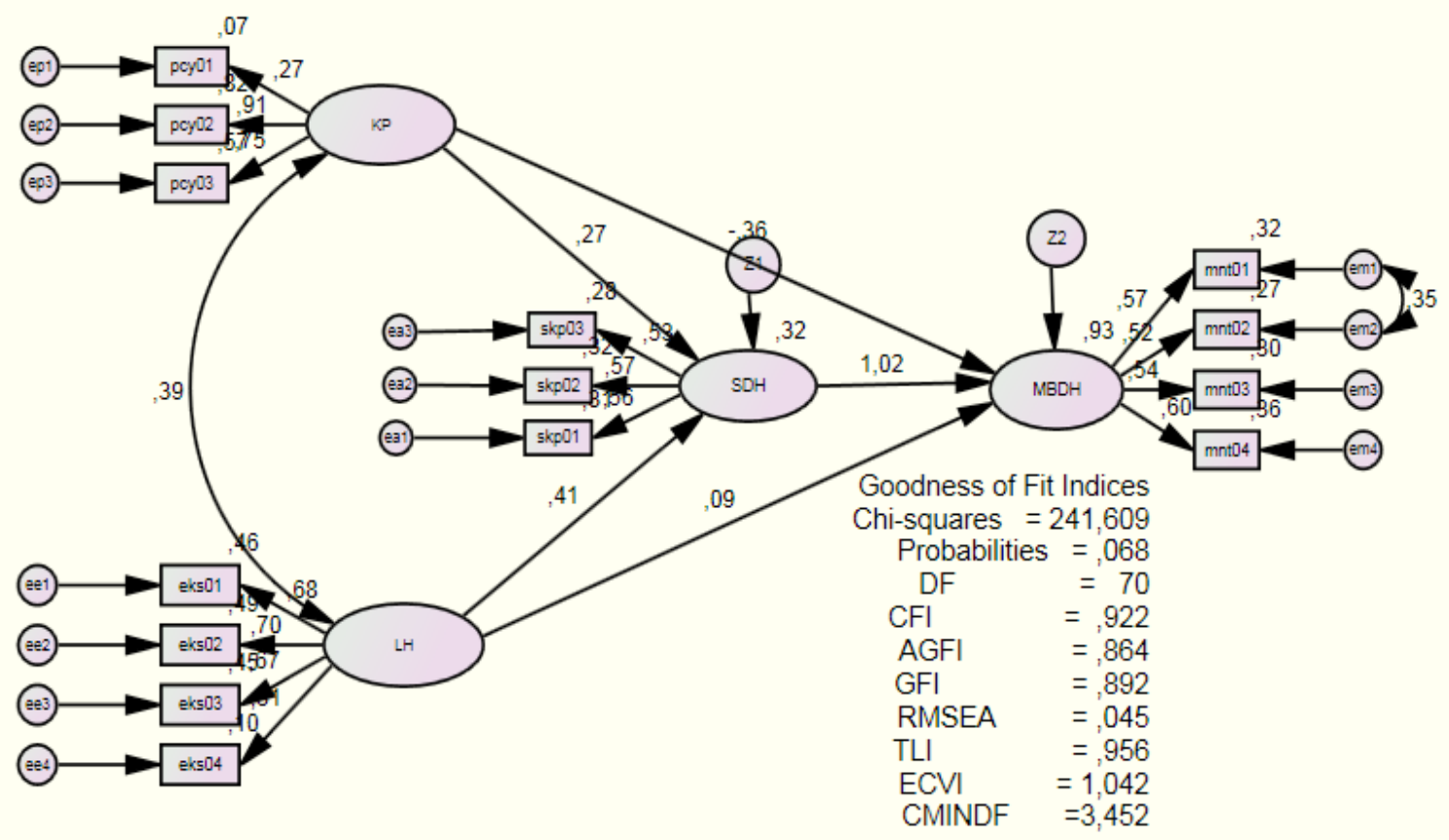

Gambar 2 Analisis SEM

\section{Hasil Pengujian Model Struktural}

Pengujian model struktural bertujuan untuk membuat penilaian apakah secara struktural antar variabel sesuai (goodness of-fit ) atau tidak. Penilaian dilakukan dengan melihat dan membandingkan angka standar kesesuian (cut-of value) dengan angka hasil perhitungan (output). Hasil analisis disampaikan pada Tabel 3. 
Tabel 3. Hasil Goodness- of-Fit Model Pengukuran Struktural

\begin{tabular}{lccc}
\hline \multicolumn{1}{c}{ Goodness of Fit Index } & Cut-off Value & Hasil analisis & Keterangan \\
\hline $\mathrm{X}^{2}$ - Chi Square & Sangat kecil & 241,609 & Baik \\
Probabilityor p value(p) & $\geq 0.05$ & 0,068 & Baik \\
CMIN/DF & $\leq 2,00$ & 3,452 & Marginal \\
RMSEA ( The Roats Mean Square & $\leq 0.08$ & 0,045 & Baik \\
Error of Aproximation) & $\geq 0.90$ & 0,892 & Marginal \\
GFI (Goodness of Fit Index) & $\geq 0.90$ & 0,864 & Marginal \\
AGFI (Adjusted Goodnes of Fit & $\geq 0.90$ & 0,956 & Baik \\
Index) & $\geq 0.90$ & 0,922 & Baik \\
TLI (Tucker Lewis Index) & & Default : 1,042 & \\
CFI (Comparative Fit Index) & ECVI $<$ IM & Saturated: 1,974 & Baik \\
ECVI ( Expected Cross Validation & & IM : 9,850 & \\
Index ) & & & \\
\hline Sumber : Analisis Data Primer & &
\end{tabular}

Hasil pengujian Goodness of Fit SEM adalah Chi-Square, $=241,609$; probability value $=0,068 ; \mathrm{CMIN} / \mathrm{DF}=3,452 ; \mathrm{RMSEA}=$ 0,$045 ; \mathrm{GFI}=0,892 ;$ AGFI $=0,864$; $\mathrm{TLI}=$ 0,956 dan $\mathrm{CFI}=0,922$. Dengan demikian model struktural secara teoritis adalah sesuai dan dapat diterima untuk dimanfaatkan untuk analisis.

\section{Pengujian Hipotesis}

Pengujian hipotesis penelitian dilakukan dengan memperhatikan model struktural, hasil angka pengujian melalui signifikansi (sig.) serta angka dan tanda koefisien regresinya. Angka standadized koefisien regresi, angka t hitung atau Critical Ratio (CR) dan sig. (probability value) disampaikan pada Tabel 4.
Pengaruh kepercayaan kepada penjual (KP) terhadap sikap daging halal (SDH), hasil perhitungan menunjukkan koefisien regresi yang positip 0,265 dengan CR positip 2,764 dan angka sig. 0,006. Angka tersebut memberikan penjelasan bahwa ada pengaruh positip yang signifikan dengan taraf signifikan pengujian dengan $\alpha=0,05$. Hal ini memberi bukti hipotesis 2 diterima. Namun pengaruh secara langsung kepercayaan terhadap penjual (KP) terhadap minat beli daging halal (MBDH) hasilnya negatif, dan signifikan. Hal ini tidak logis, dimana kepercayaan negatip, namun memberikan sumbangan sikap yang positip. Dengan demikian hipotesis ke 3 yang menyatakan ada pengaruh positip kepercayaan kepada penjual kepada minat beli daging halal ditolak.

Tabel 4 Hasil Pengujian Hipotesis

\begin{tabular}{llccll}
\hline $\begin{array}{c}\text { Pengaruh } \\
\text { Variabel }\end{array}$ & $\begin{array}{c}\text { Standardized } \\
\text { Koefisien } \\
\text { Regresi }\end{array}$ & $\begin{array}{c}\text { Critical } \\
\text { Ratio } \\
\left(\mathbf{t}_{\text {hitung }}\right)\end{array}$ & $\begin{array}{c}\text { Prob. } \\
\text { Value } \\
(\text { sig. })\end{array}$ & Kesimpulan \\
\hline $\mathrm{KP}$ & $\rightarrow \mathrm{SDH}$ & 0,265 & 2,764 & 0,006 & Sig. \\
$\mathrm{LH}$ & $\rightarrow \mathrm{SDH}$ & 0,406 & 0,790 & 0,000 & Sig. \\
$\mathrm{SDH}$ & $\rightarrow \mathrm{MBDH}$ & 1,019 & 4,032 & 0,000 & Sig. \\
$\mathrm{KP}$ & $\rightarrow \mathrm{MBDH}$ & $-0,364$ & $-0,330$ & 0,000 & Sig. \\
$\mathrm{LH}$ & $\rightarrow$ MBDH & 0,086 & 0,716 & 0,474 & Tdk Sig \\
\hline
\end{tabular}

Sumber : Analisis Data Primer

Kemudian pengaruh Label Halal (LH) yang menjelaskan tulisan, sertifikat, logo atau label halal toko terhadap sikapnya $(\mathrm{SDH})$ berdasarkan hasil perhitungan menunjukkan angka positip 0,406 dengan angka CR positip 0,790 dan sig. 0,000 . Hal ini dapat membuktikan hipotesis 4 bahwa ada pengaruh yang sifatnya positip dan signifikan, 
antara label halal kepada sikap daging halal. Namun berdasarkan hasil perhitungan dan analisis secara langsung antara label halal (LH) terhadap minat beli daging halal dengan menggunakan tingkat signifikansi pengujian $\alpha$ $=0,05$ tidak berpengaruh secara signifikan, hal ini dapat dijelaskan dengan angka sig. sebesar 0,474 . Hasil ini menyebabkan hipotesis ke 5 tidak dapat diterima.

Sedangkan sikap terhadap daging halal (SDH) kepada minat beli daging halal (MBDH) menunjukkan angka koefisien regresi sebesar 1,019 dengan CR 4,032 dan sig. 0,000. Hasil ini menunjukkan bahwa ada pengaruh yang positip dan signifikan antara sikap daging halal dengan minat belinya. Dengan demikian hipotesis ke 1 yang menyatakan ada pengaruh positip antara sikap daging halal kepada dengan minat beli daging halal dapat diterima atau terbukti.

\section{Diskusi}

Hasil penelitian ini memberikan informasi dan penjelasan bahwa konsumen lebih mempercayai kepada penjual yang telah mereka kenal dalam menyediakan daging halal. Oleh sebab itu maka penjual yang muslim atau yang berpakaian sesuai dengan syariah Islam lebih mereka percayai dan menjadi tempat pilihan membeli. Temuan bahwa faktor sinyal (cues) menjadi alat bagi konsumen berperan sebagai stimuli dalam membentuk sikap dan minatnya ini sejalan dan memperkuat hasil studi dan penelitian sebelumnya oleh Cox ( 1967) Olson ( 1972) dan Szibyllo \& Jacoby ( 1974). Sedangkan temuan bahwa faktor penjual muslim mempunyai pengaruh yang positip dan signifikan terhadap sikap konsumen terhadap daging halal, sesuai dengan hasil penelitian Bonne et al., 2007 di Belgia dan Hariri, 2009 di Inggris. Namun secara langsung faktor penjual ini tidak mempunyai pengaruh yang positip dan signifikan terhadap minat beli daging halal.

Simbul-simbul seperti sertifikat, logo dan label halal menjadi informasi penting bagi konsumen dalam penelitian ini dalam menentukan sikap terhadap daging halal. Hal ini sesuai dengan penelitian yang dilakukan oleh Abdul et al. di Malaysia (2009); Ireland dan Rajazabdeh di UEA (2011) yang menyatakan bahwa sertifikat halal dan logo mempunyai pengaruh terhadap sikap dan minat beli. Simbul yang berupa sertifikat halal, logo atau label halal yang dipajang pada toko atau outlet penjualan merupakan salah satu alat komunikasi, ternyata cukup penting bagi calon pembeli menjadi pertimbangan untuk membeli atau membatalkan keputusannya. Oleh sebab itu simbul ini juga dapat merupakan alat bagi penjual atau perusahaan sebagai salah satu unsur strategi pemasaran. Sertifikat, logo atau label halal agar mempunyai peranan dalam membentuk minat beli konsumen berdasarkan temuan penelitian ini harus melalui sikapnya, dan hasil penelitian menjelaskan bahwa faktor ini tidak memiliki pengaruh yang positip dan signifikan terhadap minat beli daging halal. Hasil penelitian menyatakan bahwa sikap mempunyai pengaruh yang signifikan terhadap minat beli, dari hasil penelitian ini memperkuat Teory of Reasoned Action dari Fishbein dan Azjen( 1975).

\section{KESIMPULAN DAN IMPLIKASI HASIL PENELITIAN}

Hasil penelitian dapat disimpulkan kepercayaan pada penjual dan label halal mempunyai peran yang signifikan dalam membentuk sikapnya. Minat beli daging halal konsumen muslim di Indonesia dipengaruhi oleh sikapnya. Hasil ini memperkuat TRA dari Fishbein dan Ajzen, 1975. Kepercayaan pembeli daging halal kepada penjual dan label halal dapat sebagai faktor latar belakang atau antecedent terhadap sikap terhadap daging halal mempunyai pengaruh yang positip dan signifikan adalah temuan pokok dari penelitian ini. Hal ini merupakan kontribusi yang dapat disampaikan secara teoritis maupun untuk kepentingan praktis.

Dengan demikian, sebagai implikasi dan aplikasi, maka institusi atau individu seorang penjual daging dan jaringan penyedia daging halal harus dapat menjaga integritas dan menjaga image karena mereka disikapi dan telah dipercaya dalam pengadaan daging halal. Sedangkan label halal pada produk, outlet, toko atau kios penjual merupakan informasi penting bagi konsumen untuk meyakini bahwa daging yang dijualnya halal, oleh sebab itu penjual sangat berkepentingan dan perlu untuk memiliki sertifikat atau label halal yang diperoleh dari lembaga independen yang mempunyai otoritas dibidang sertifikat halal. 
Selanjutnya apabila telah memiliki sertifikat dan label halal perlu dikomunikasikan kepada konsumen yang menjadi tergetnya.

\section{REFERENSI}

Abdul, A. Y. and Vui, C. N. (2012), "The role of halal awareness and halal certification in influencing non-muslims' purchase intention", 3rd International Conference on Business and Economic Research (ICBER) proceeding. Bandung: 12-13 March 2012 ISBN: 978-967.5705.05-2

Abdul, A. Y. and Vui C.N. (2013), "The Role of Halal Awareness, Halal Certfication, and Marketing Components in Determining Halal Purchase Intention Among NonMuslims in Malaysia: A Structural Equation Modeling Approach", Journal of International Food \& Agribusiness Marketing. Volume 25 Issue 1, pp.1-23.

Abdul, M., Ismail, H., and Johari, Y. (2009), "Consumer Decision making process in shopping for halal food in Malaysia", China-USA Business Review, Vol.8 No.9, Serial No.75 September, ISSN 1537-1514 USA.

Abdul, K. A. (2014), "Young consumer's attitude towards halal food outlets and JAKIM's certification in Malaysia". Procedia-Social and Behavioral Science. 121 pp.26-34.

Abdullah, A. (2013), "Mengenal daging sehat dan halal" Serambinews.com Network, diunduh, Jum'at, 5 April 2013.

Ahmed, A. (2008), "Marketing of halal meat in the United Kingdom: Supermarkets versus local shops", British Food Journal, Vol. 110 No. 7, pp. 655-670.

Ahmad, Z. ( 2010 ), “ Factors Affecting Food Product Marketing in Islamic Perspective and How Producers and Planners can sell their Products in Islamic Countries". Interdisciplinary Journal of Contemporary Research in Business. June. Ulric's Periodical, Vol.2 No.2, pp.342-360.
Ajzen, I. (1991), "The theory of planned behavior", Orgazizational Behavior and Human Decision Process, 50, pp.179211.

Ajzen, I. (2002), "Perceived behavioral control, self-efficacy, locus of control, and the the-ory of planned behavior", Journal of Applied Social Psychology, 32, pp.665-683.

Ajzen, I. (2005), Attitudes, Personality, and Behavior, (2 ${ }^{\text {nd. }}$ Edition$), ~ M i l t o n-K e y n e s$, England: Open University Press / McGraw-Hill.

Akhter, W., Hussain, T. (2012 ), "Taka ${ }^{-}$ful standards and customer perceptions affecting taka ${ }^{-}$ful practices in Pakistan: a survey". International Journal of Islamic and Middle Eastern Finance and Management, Vol. 5 No. 3, pp. 229240.

Al Qur'an dan Terjemahannya Departemen Agama Republik Indonesia, tanpa tahun terbit.

Apriyantono, A. (2012), Prinsip-prinsip haram dan halal, diunduh dari www. Pusat halal.com, 21 Desember 2013.

Bagozi, R.P. (1981), “Attitudes, intentions and behavior: A test of some key hipotheses", Journal of Personality and Social Psychology, Vol.41, pp 46-61.

Baron, R. and Byrne, D. (2002), Social Psychology, $5^{\text {th }}$ edition, Boston: Allyn\&Bacon.

Berkowitz, L (1972), Social Psychology, Glenview: Scott, Foresman and Company.

Biro Pusat Statistik (BPS) (2014), http://www. bps.go.id. diakses September 2015.

Bonne, K. and Verbeke, W. (2008), "Muslim consumer trust in halal meat status and control in Belgium", Meat Science. Vol.79 No.1, p113-123.

Bonne, K. and Verbeke, W. (2008), "Religious values informing halal meat production 
and the control and delivery of halal credence quality", Agriculture and Human Values Vol. 25 No.1, pp.35-47.

Bonne, K., Vermeir, I., Bergeaud B. F. and Verbeke, W. (2007), "Determinants of halal meat consumption in France", British Food Journal, Vol. 109 No. 5, pp.367-386.

Byrne, B.M. (2010), Structural Equation Modelling With AMOS Basic Concept, Application and Programming, Lawrence Erbaum Associates.

Chiou, J.S. (1998), “The Effects of Attitude, Subjective Norm, and Perceived Behavioral Control on Consumers' Purchase Intentions: The Moderating Effects of Product Knowledge and Attention to Social Comparison Information", Proc Natl. Sci. Counc. ROC (C), Vol. 9 No. 2, pp. 67-81.

Chen, W. (2013), “The effects of different types of trust on consumer perceptions of food safety: An empirical study of consumers in Beijing Municipality", China Agricultural Economic Review. Vol.5, pp.34-48.

Cox, D.F. (1967), “The Sorting Rule Model of Consumer Product Evaluation Process", Risk Taking and Information Handling in Consumer Behavior, Boston, GSBA, Harvard University.

Feldman, R.S. (1995), Social Psychology, New Jersey: Prentice Hall.

Ferdinand, A. (2006), Structural Equation Modelling Dalam Penelitian Management : Aplikasi ModelModel Rumit dalam Penelitian untuk Tesis Magister dan Disertasi Doktor, Semarang : Badan Penerbit Universitas Diponegoro. ISBN 979.704.233.2.

Fishbein, M. and Ajzen, I. (1975). Beliefs, Attitude, Intention and Behavior, New Yok:Addison-Wesley Company, INC.

Ghazaly, A. S. (2013), “Awareness and
Demand for $100 \%$ Halal Supply Chain Meat Products", Procedia- Social and Behavioral Science 130, pp.167-178.

Ghozali, I. (2013), Model Persamaan Struktural Konsep dan Aplikasi dengan Program AMOS 21.0, Semarang: Badan Penerbit Universitas Diponegoro.

Hair, J.F., Ralph, E.A., Ronald, L.T, and William, C. B. (2006), Multivariate Data Analysis, $5^{\text {th }}$ ed. Upper Saddle River, NJ: Prentice Hall.

Hariri, B. (2009), "Determinants of Halal Meat Consumption in London", Theses, University of Gloucestershire UK.

Hasbi, I. ( 2004), Halal dan Haram dalam Makanan, cetakan I, Jakarta: Permadani.

Hogg, M.A. and Vaughan, G.M. (2005), Introduction to Social Psychology, Sidney, Australia: Prentice Hall.

Ireland, J. and Rajazabdeh, S. A. (2011), "UAE consumer concerns about halal products". Journal of Islamic Marketing. Vol.2 No.3. pp.274-283.

Jonathan, A.J.W. and Jonathan, L. (2010), "Shaping the Halal into a brand?" Journal of Islamic Marketing, Vol. 1 No. 2, pp.107-123.

Jusmaliani and Nasution, H. (2008), "Religiousity Aspect in Consumer Behavior: Determinants Halal Meat Consumption", Asean Marketing Journal,Vol.2, pp.35-47

Kaleeli, H. (2010), "Halal meat: the truth", Work Paper, dalam www. Info meat, diunduh 20 Mei 2013.

Kotler, P. and Keller, K. L. (2012), Marketing Management $14^{\text {th }}$, Global Edition, New York: Pearson.

Kotler,P and Amstrong, G (2016), Principles of Marketing, sixteenth edition, London: Pearson.

Malhotra, N.K. (1996), Marketing Research, New Jersey: Prentice-Hall Int. Inc. 
MUI (2014), Persyaratan sertifikasi halal LPPOM MUI (Kebijakan, Prosedur, dan Kriteria) HAS 23000. Jakarta : LPPOM MUI.

Mukhtar, A. and Butt M.M. (2012), "Intention to choose Halal products: the role of religiosity", Journal of Islamic Marketing, Vol. 3 No.2, pp. 108-120.

Olson, J.C. (1972), “ Cue Utilization in the Quality Perception Process: A cognitive Model and an Empirical Test", Disertation, Purdue University.

Rajagopal, S., Ramanan, S., Visvanathan, R. and Satapathy, S.(2011), "Halal certification: implication for marketers in UAE", Journal of Islamic Marketing, Vol.2 No:2, pp.138-153.

Riaz, M. N. (1999), "Examining the halal market", Prepared Foods, Vol. 68 No. 10, pp.698-704.

Riaz, M.N and Chaudry, M.M. (2004), Halal Food Production, Boca Raton, FL: CRC Press.

Riaz, M.N. and Chaudry, M.M.(2004), "The Value of Halal Food Production", Internati-onal News on Fats, Oils and Related Materials, INFORM, Vol.15, pp.11-23.

Salman, F. and Siddiqui, K. (2011), “An exploratory study for measuring consumers awareness and perceptions towards halal food in Pakistan"
Interdisciplinary Journal of Contemporary Research in Business, Vol. 3 No:2, pp.639-652.

Schiffman, L.G. and Kanuk, L.L. ( 2010 ), Consumer Behavior, tenth edition, Upper Saddle River, New Jersey: Prentice Hall Pearson.

Sekaran, U. ( 2003), Research Methods For Business: A Skill Building Approach, New York : John Willey \& Sons, Inc.

Shah, A. S., Sayuti, M., Nazura,M. (2011), "Applying the Theory of Planned Behavior (TPB) in halalfood purchasing", International Journal of Commerce and Management Vol. 21 No.1, pp. 8-20.

Szybillo, G.J. and Jacoby, J. (1974). “Intrinsic versus extrinsic cues as determinants of perceived product quality", Journal of Applied Psychology, Vol. 59, No., pp. 74-78

Tieman, M., Ghazali, M. C. and Vorst, J.G.and Van D.A.J. (2013), "Consumer perception on halal meat logistics", British Food Journal, Vol. 115 No. 8, pp. 1112-1129.

Tieman, M. and Ghazali M.C. (2014), "Halal control activities and assurance activities in halal food logistics", Procedia- Social and Behavioral Science 121, pp.44-57.

UU Republik Indonesia No. 33 tahun 2014 tentang Jaminan Produk Halal. 